\title{
THE NATURE OF THE INCREASED PULMONARY VASCULAR RESISTANCE IN MITRAL STENOSIS
}

BY

\author{
E. G. WADE, J. MACKINNON, AND C. F. H. VICKERS
}

From the University Department of Cardiology, Manchester Royal Infirmary

It has been known for many years that in certain cases of mitral stenosis the pulmonary arterial pressure may be disproportionately high. More recently it has been shown that this pressure, which is due to an increase in the pulmonary vascular resistance, may rise still further on effort (Bayliss et al., 1950; Eliasch et al., 1952). There is considerable debate as to the mechanism and significance of this increase in pulmonary vascular resistance for, as the author of a recent annotation in the Lancet remarked, "it is not fully understood."

In view of its theoretical and practical importance we decided to reinvestigate this problem with especial reference to the role of the autonomic nervous system. In a previous paper we reported the results of injecting adrenergic-blocking agents into the pulmonary artery in cases of mitral stenosis (Mackinnon et al., 1956), concluding that they had no effect. In this paper we report the effects of hexamethonium bromide and of atropine. We find that hexamethonium will frequently lower the high resistance, but will bring forward evidence that this is an indirect action secondary to lowering the pulmonary capillary or venous pressure and independent of the autonomic system. We find that atropine has no consistent effect on pulmonary dynamics.

\section{MATERIAL AND Method}

The material consisted of 18 patients suffering from mitral stenosis, all of whom had attended the Department of Cardiology at the Manchester Royal Infirmary. They were all examined in the usual manner. All were subjected to cardiac catheterization; three grains of seconal and $0.5 \mathrm{ml}$. of procaine amide were given one hour beforehand and all pressures were recorded electrically by means of a capacitance manometer. Systemic pressures were obtained through a Cournand needle placed in the brachial artery. Mean pressures were obtained by electrical damping and all pressures were referred to a point $5 \mathrm{~cm}$. below the sternal notch. Blood gases were analysed on the Van Slyke-Neill manometric apparatus and expired air was collected in a Tissot spirometer and analysed on the Haldane apparatus.

Ten patients were selected because there was clinical evidence of pulmonary hypertension. At catheterization, after the basal measurements had been made, they were exercised on a bicycle-ergometer. The work varied in degree from patient to patient according to their capacity, the oxygen consumption usually varying from 250 to $400 \mathrm{ml} . / \mathrm{m} .{ }^{2} / \mathrm{min}$. The effort was invariably continued at a constant rate for six minutes, the output being estimated again between the fourth and sixth minutes; this was considered sufficient time for a steady state to be obtained (Eliasch et al., 1952; Donald et al., 1954) and this was confirmed by minute to minute measurements of pressures and pulse rate. After a period of fifteen to thirty minutes for recovery, checked by frequent pressure and pulse readings, hexamethonium bromide was injected through the cardiac catheter and the circulatory measurements repeated at rest and under identical conditions of exertion. The dose of hexamethonium was that which had been previously found, when administered intravenously, to cause a postural fall in systemic pressure of at least $25 \mathrm{~mm} . \mathbf{H g}$, and the timing of the subsequent outputs was so arranged as to fall in the period of maximal effect. This dose varied from 8.5 to $12.5 \mathrm{mg}$. In the first seven observations the "wedge" or pulmonary capillary venous pressure (PCV) was measured only during the initial output; in the last three, it was measured during each output period. It proved impossible to exercise one patient (Case 5). One patient (Case 1) was re-catheterized four weeks after a successful mitral valvotomy. 
Eight patients selected because they had auricular fibrillation and were fully under the influence of digitalis were given, after the resting measurements had been made, an injection of atropine through the catheter, the dose being from $1 / 120$ to $1 / 75$ of a grain. Seven of the patients were not exercised, the measurements being repeated under resting conditions; the eighth was exercised in the manner previously described before and after the administration of atropine.

Resistances were expressed in c.g.s. units and were calculated as follows.

$$
\begin{array}{ll}
\text { Total Pulmonary Resistance } & =\left(\mathrm{PA}_{\mathrm{m}}-5\right) \times 1332 / \mathrm{C} . \mathrm{O} . \text { in ml. } / \mathrm{sec} . \\
\text { Pulmonary Vascular Resistance } & =\left(\mathrm{PA}_{\mathrm{m}}-\mathrm{PCV}\right) \times 1332 / \mathrm{C} . \mathrm{O} . \text { in ml. } / \mathrm{sec} . \\
\text { Systemic Resistance } & =\mathrm{BA}_{\mathrm{m}} \times 1332 / \mathrm{C} .0 . \text { in ml. } / \mathrm{sec} .
\end{array}
$$

where $\mathbf{P A}_{\mathrm{m}}$ is the mean pulmonary arterial pressure, $\mathbf{B A}_{\mathrm{m}}$ is the mean systemic pressure recorded in the brachial artery, PCV is the mean pulmonary capillary or "wedge" pressure, and C.O. is the cardiac output.

Ventricular work was calculated in terms of pressure-work only, namely, $W=P V$, where $P$ is the mean pressure in metres of blood and $V$ is the output in litres per hour, and was expressed in $\mathrm{Kg}$. metres per hour.

\section{RESULTS}

Hexamethonium Bromide. There was a fall in resting mean pulmonary arterial pressure in seven observations, the greatest drop being $13 \mathrm{~mm} . \mathrm{Hg}$. In one case the mean pressure rose and in three there was no appreciable change (Fig. 1A). When a fall occurred, the systolic pressure was always affected more than the diastolic. Exercise invariably caused the pulmonary artery pressures to rise; following hexamethonium this increase was less in six cases, greater in three, and unchanged in one (Fig. 1B). Changes in cardiac output were minimal and inconsistent and the pulse rate was generally unaltered.

A

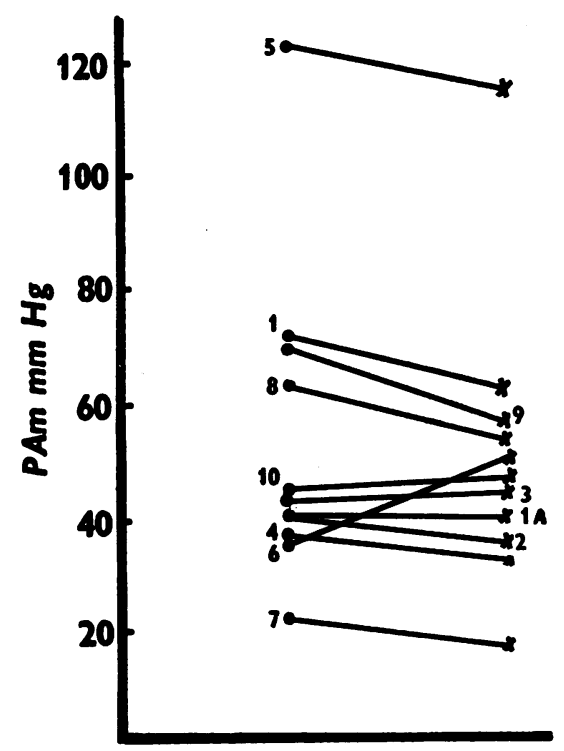

B

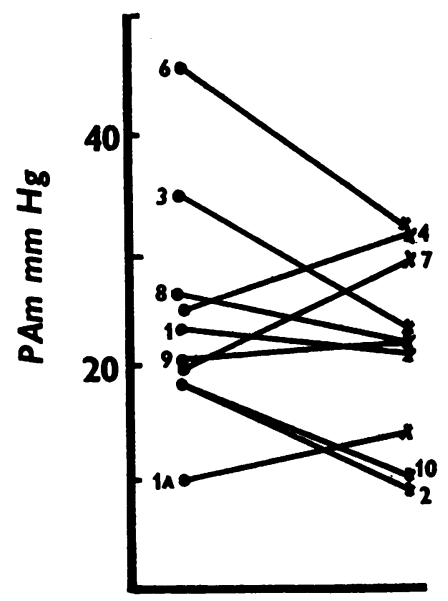

FIG. 1.-(A) The effect of hexamethonium on the resting P.A. mean pressure. (B) The change in P.A. mean pressure resulting from exercise. ( $\bullet=$ before, and $X=$ after hexamethonium.)

Resting total pulmonary resistance was variably affected in eight observations, there being a tendency to fall in five and to rise in three; it remained virtually unchanged in two (Fig. 2A). Expressed as a proportion of the initial basal resistance, the change was less than 10 per cent in five 


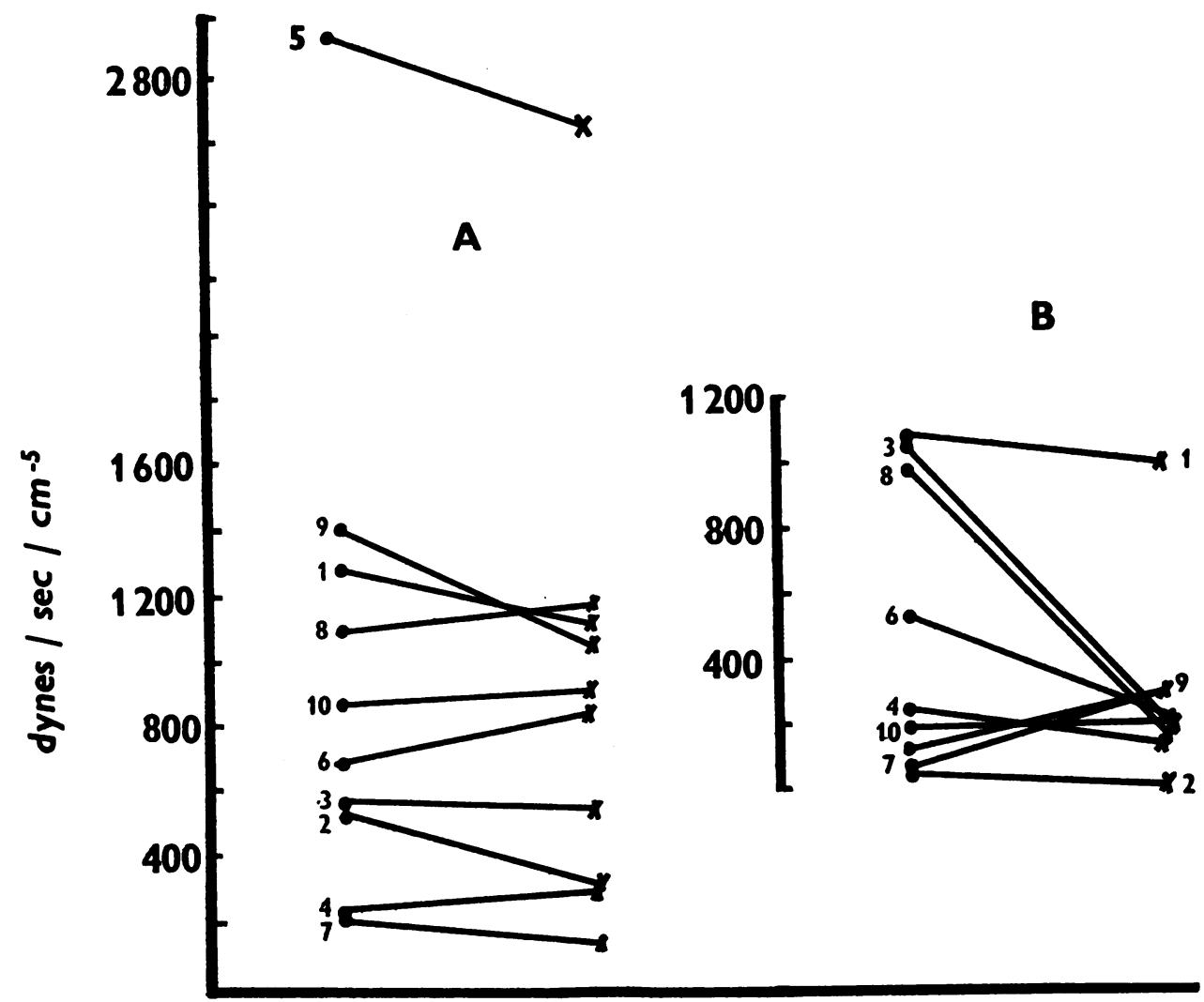

FIG. 2.-(A) The effect of hexamethonium on resting T.P.R. (B) The change in T.P.R. resulting from exercise. ( $\bullet=$ before, and $\mathrm{X}=$ after hexamethonium.)

cases, fell by more than 20 per cent in three, and rose by more than 15 per cent in two (Fig. 3A). There was an increase in resistance on effort in all cases. Hexamethonium diminished the absolute extent of the increase to a variable degree in six cases; in two it was slightly augmented and in one it was unchanged (Fig. 2B). Expressed proportionately, after hexamethonium the increase on effort was altered by less than 10 per cent in four cases, diminished by more than 40 per cent in four, and increased by over 50 per cent in one (Fig. 3B). The most striking absolute and proportional " blocking " of the increased resistance on effort was achieved in Cases 3, 6, and 8, none of which had shown a fall in resting resistance. All three patients noticed subjective improvement on exercising after hexamethonium. There is, therefore, no apparent relation between the effects of hexamethonium on the resting resistance and the extent of the increase in resistance occurring on effort (c.f. Fig. 2A and $B$ and $3 A$ and $B$ ).

There was a fall in the resting $P C V$ pressure after hexamethonium in two of three cases (8 and 9), while in the third there was a slight rise (10) (Fig. 4). In Cases 8 and 9 the extent to which the $P C V$ rose on effort was also diminished; in Case 10 there was no change. In Fig. 4 the pulmonary vascular resistance at rest and on effort before and after hexamethonium is related to the $P C V$ pressure; there is a direct relation, both in individual cases and in the three cases taken together $(r=+0 \cdot 59: \mathrm{I} / \sqrt{ } N-I=0 \cdot 61)$.

The work performed by each ventricle varied considerably from case to case. With the exception of Case 1, effort always caused a rise in right ventricular work; after hexamethonium the degree of this rise was increased in six cases, diminished in one, and unchanged in two. The left ventricular work pattern was rather different. In three cases $(1,3$, and 8$)$ effort caused a fall in the work done and, in two of them ( 3 and 8 ), this was converted into a rise after hexamethonium. These 
A

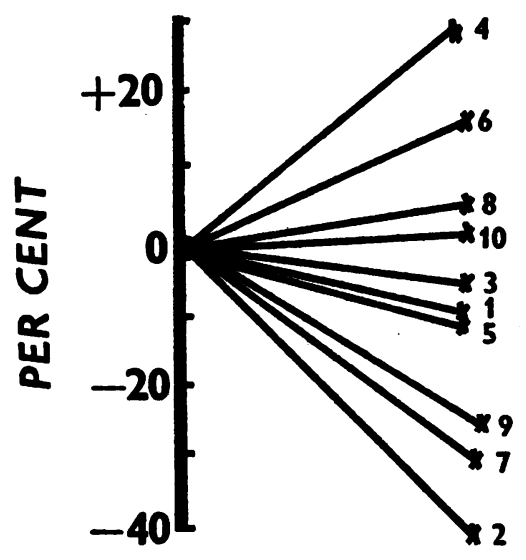

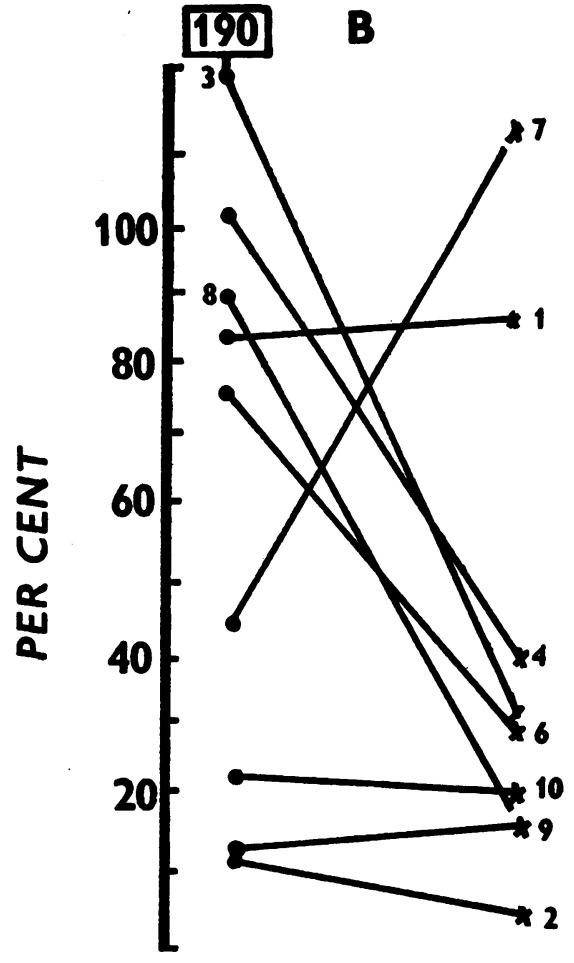

Fig. 3.-(A) The effect of hexamethonium on resting T.P.R. expressed as a percentage. (B) The effect on the rise in T.P.R. on effort expressed as a percentage of the initial T.P.R. ( $\bullet=$ before, and $X=$ after hexamethonium.)

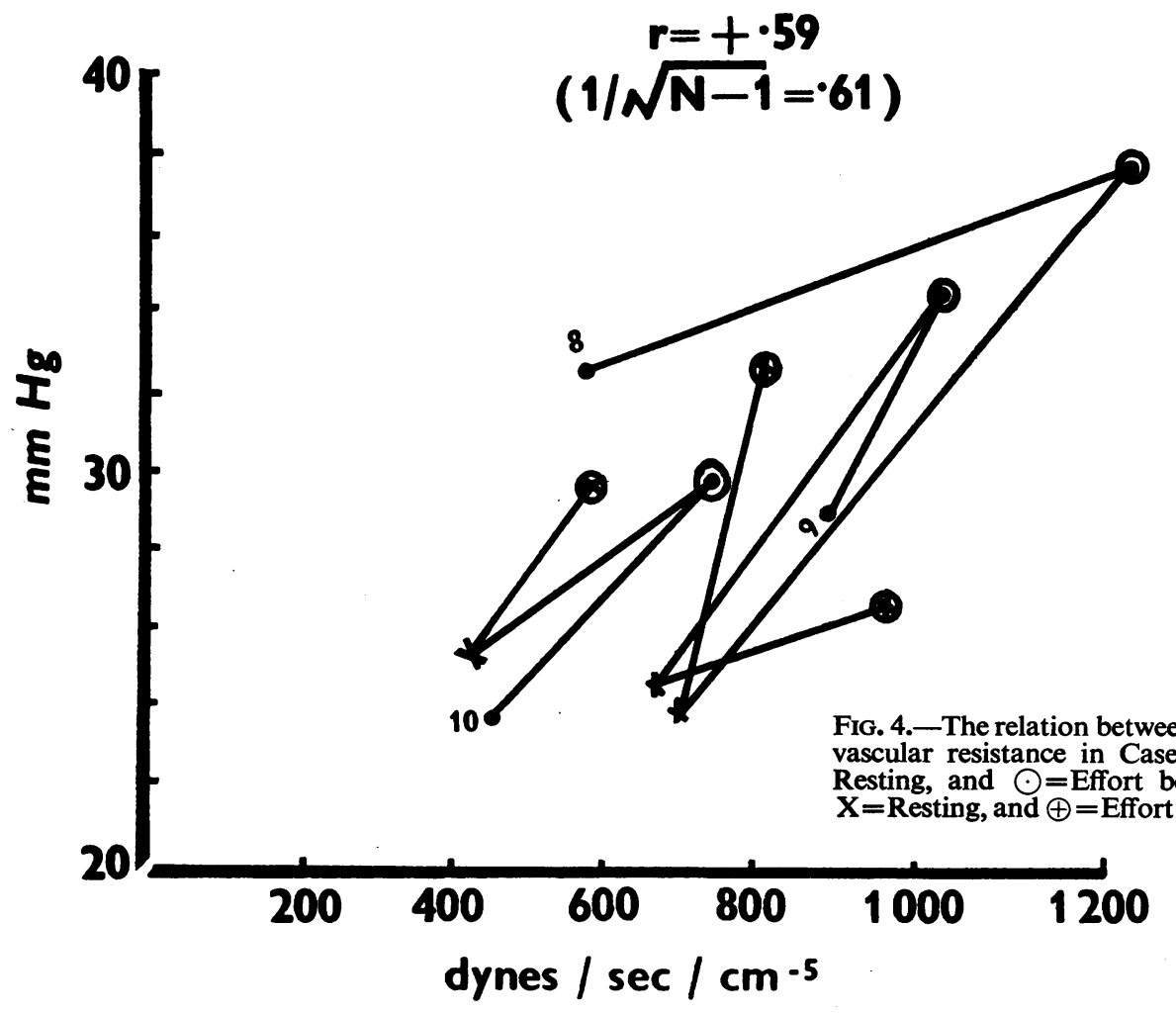


RIGHT

VENT. WORK
LEFT

VENT. WORK

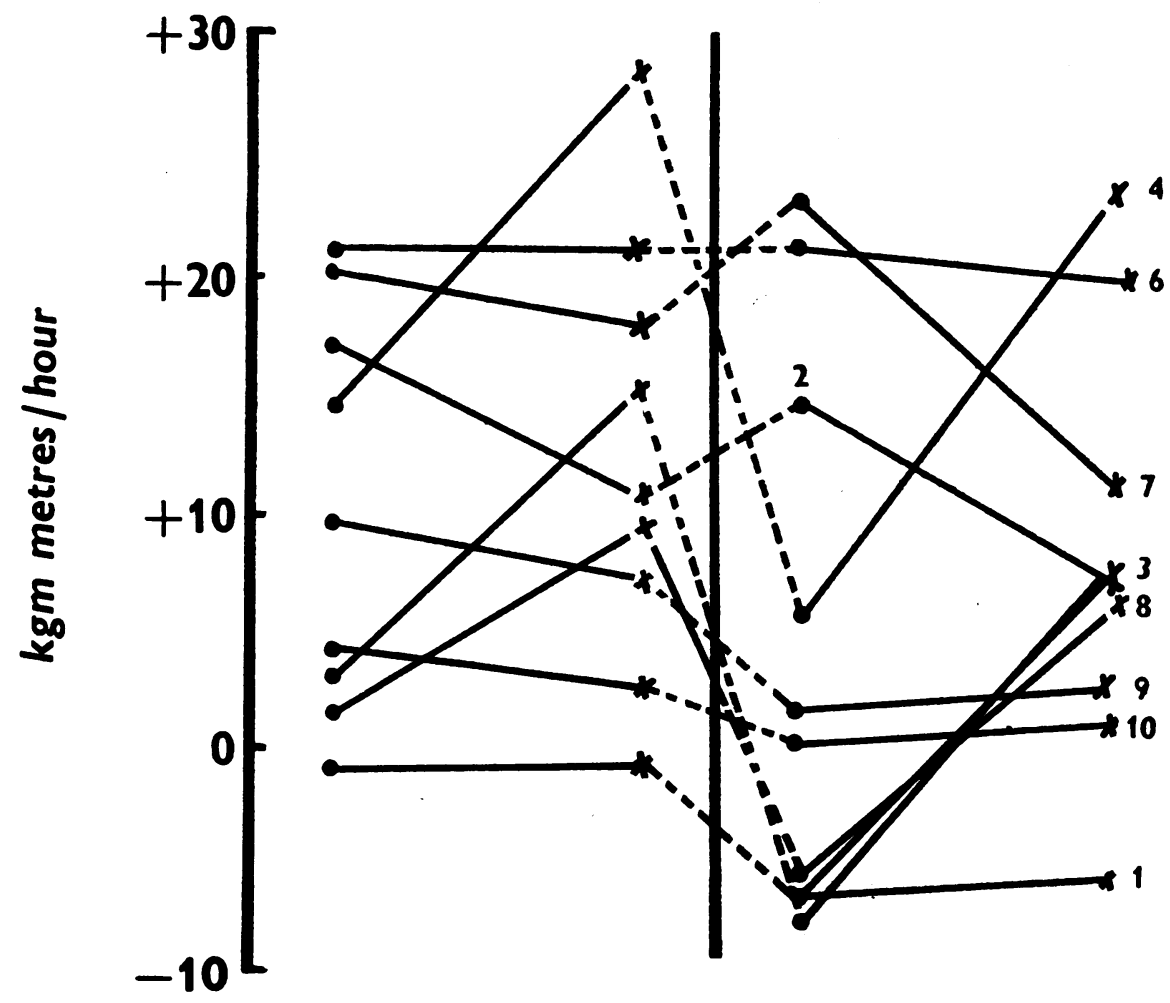

FIG. 5.-The changes in right and left ventricular work occurring on effort before (closed circles) and after (crosses) hexamethonium. The interrupted lines connect the same patient.

were two of the three cases in which hexamethonium had the most striking " blocking" effect on rise in pulmonary hindrance on effort. In all other cases left ventricular work increased on effort to an extent that was unchanged by hexamethonium in four cases, slightly diminished in two, and increased in one. These results are summarized in Fig. 5.

Case 1 was recatheterized four weeks after successful mitral valvotomy. Although hexamethonium, prior to operation, had produced only a small fall in total pulmonary resistance from 1310 to 1150 units, it subsequently fell to 500 units. Moreover, the increase in resistance occurring on effort, unaffected before operation by hexamethonium, was decreased from over 1000 to 55 units (Fig. 6). The resting $P C V$ pressure was reduced from 25 to $7 \mathrm{~mm}$. Hg. Owing to a technical fault the resting outputs after operation were unreliable, but comparison may reasonably be made between the effort patterns under the influence of identical doses of hexamethonium.

Atropine. There was no consistent effect either upon pressures or upon resistances. The mean P.A. pressure rose appreciably in Cases 12 and 13; the $P C V$ rose from 27 to $31 \mathrm{~mm}$. $\mathrm{Hg}$ in Case 12 but was not obtained in Case 13. In both there was an increase in the pulse rate of over 20 beats a minute. In Case 16 total pulmonary resistance fell by 200 units but in the remainder there was no significant change. Changes in cardiac output were small and inconsistent. Only one case (18) was exercised before and after atropine; neither the resistance nor the output was appreciably affected. The pulse rate on effort was 120 before and 140 after the drug. 


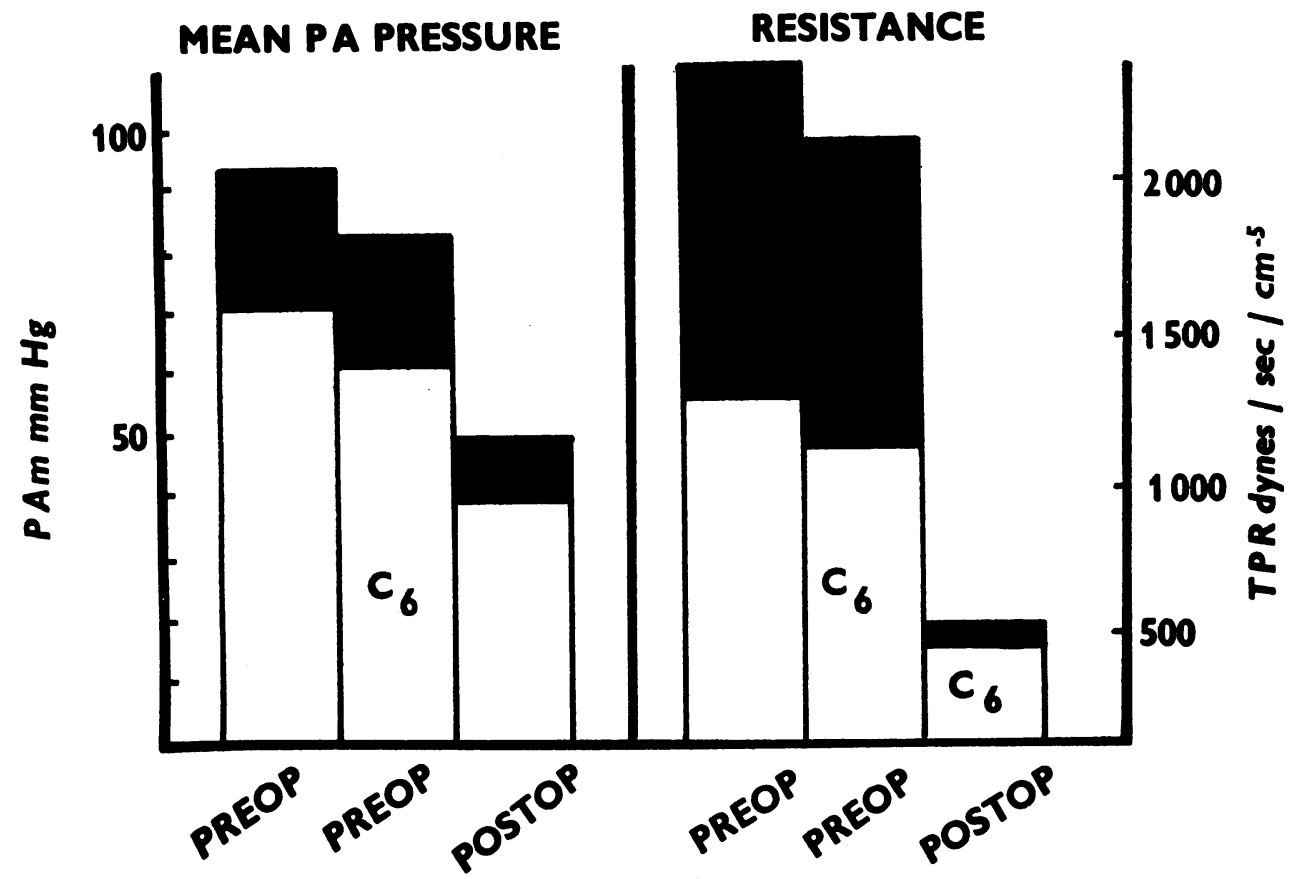

FIG. 6. - The effect of hexamethonium on P.A. mean pressure and T.P.R. in Case 1, together with the finding one month after successful valvotomy. White $=$ resting. Black $=$ increment on effort. $\mathbf{C}_{6}=$ hexamethonium.

\section{DisCUSSION}

Hexamethonium caused a fall in resting mean pulmonary arterial pressure in the majority of our cases and this harmonizes with the findings of Davies et al. (1954), Storstein and Tveten (1954), Halmagyi et al. (1953) and Scott et al. (1955). In terms of resistance, however, the change is trivial in five cases, such pressure changes as occur being ascribable to alteration in cardiac output. In two others the resting resistance actually increased, so that there was a significant fall in only three of the ten cases. Unfortunately Davies et al. did not calculate the pulmonary resistance, while Halmagyi et al. used the pulmonary arterial systolic pressure in calculating resistance and we have noted that the systolic pressure was invariably affected to a greater extent than the mean. With the exception of Storstein and Tveten, all these authors interpreted their results as evidence that the autonomic nervous system participated in maintaining the high pressure. A similar conclusion was reached by Meriel et al. (1953) on the grounds that hydergine, an adrenergic-blocking agent, would also reduce the pulmonary hypertension of a variety of clinical conditions. Comparison of the effect of hexamethonium upon resting and exertional dynamics throws some doubt on the validity of this conclusion, for the greatest effect on the two patterns was not necessarily seen in the same case; it is reasonable to anticipate that this would have been so if the resistance, in both instances, was a matter of simple sympathetic overactivity (Fig. 1, 2, and 3). There are certain other objections to this concept of sympathetic overactivity: no physiological mechanism is known involving sympathetic control of pulmonary vessels, adrenalin does not cause pulmonary hypertension in normal subjects (Witham and Fleming, 1951), and we have been unable to confirm that hydergine or priscol (2-benzyl-2-imidazoline) will lower the pulmonary resistance in mitral stenosis (Mackinnon et al., 1956). It may be argued that, whereas the rise in hindrance on effort is vasoconstrictive, a high resting hindrance unaffected by hexamethonium means a degree of irreversible structural change. This concept of combined structural and vasospastic narrowing has been put 
forward to account for the frequent failure of both ganglion-blocking and adrenergic-blocking agents, to lower raised pulmonary pressures (Meriel et al., 1953; Scott et al., 1955). It is difficult to explain, on this basis, the paradoxical findings in Cases 8 , in which resting pulmonary vascular resistance is not affected but the vasoconstriction response to effort is largely prevented, and 9, in which resting resistance falls but the vasoconstriction response still occurs. Scott et al. have even gone so far as to suggest that the response to a ganglion-blocking agent, in their case tetraethyl-ammonium chloride (T.E.A.C.), will serve to differentiate cases in which a good or poor result may be expected from mitral valvotomy. In our Case 1 hexamethonium had singularly little effect on the resting or exercise patterns but, within four weeks of operation, pulmonary hindrance had fallen to one-fifth of its former value and there was almost no rise on effort (Fig. 6). Werko, et al. (1952) have also reported large falls in pulmonary vascular resistance in cases of mitral stenosis within a month of operation, providing that the $P C V$ pressure was satisfactorily reduced. Clearly the initial high resistance in our case must have been largely due to vasocontraction and not to irreversible structural change. Equally clearly, ganglion-blocking drugs must not be used to select cases for surgery.

It has long been known that there is a direct relation between the $P C V$ pressure and the pulmonary vascular resistance, and that, although a high $P C V$ may occur with a normal resistance, a high resistance always implies a high $P C V$ (Eliasch et al., 1952; Wade, 1952; and Wood, 1954). In those of our cases in which it was measured on each occasion, $(8,9$, and 10) there was a direct relation between $P C V$ and resistance, and hexamethonium did not reduce the hindrance without a fall in $P C V$. An indirect action through an effect on $P C V$ pressure would explain the differing effect on resistance at rest and on effort, the diminution in respiratory distress experienced by Cases 3 and 8 when exercising after hexamethonium and also the observation of Davies et al., otherwise inexplicable, that pulmonary œdema was relieved by hexamethonium in two of their cases. Such an indirect action would permit explanation of the failure of hexamethonium to reduce the resistance in Case 1, despite a rapid fall following successful valvotomy. Only one other study of the effects of hexamethonium in which PCV pressures were recorded has been reported (Scott et al., 1955): it fell in only one of three cases in which the pulmonary vascular resistance was reduced. Their results are not entirely comparable with ours, for they used T.E.A.C., in doses so large that there were substantial falls in the systemic pressure with the patients lying down. There may thus have been considerable pooling of blood in the systemic circuit. We suggest that the concept that changes in pulmonary vascular resistance following hexamethonium are linked to, and dependent on, changes in $P C V$ pressure is entirely consonant with our findings and we consider it to be the most reasonable hypothesis. It would also accord with the observation made by Wade and Ball (1956) that, in unexplained pulmonary hypertension with normal PCV pressures, hexamethonium is without effect.

There are several ways in which hexamethonium might affect the $P C V$ pressure. It has been shown that the lung blood volume is directly related to the capillary pressure (Kopelman and Lee, 1951; Wade et al., 1952) and, on exercise, both pressure and volume tend to rise (Wade, 1952) Storstein and Tveten, in a careful analysis, concluded that the effects of hexamethonium could be explained by reduction in pulmonary blood volume due to pooling of blood in the systemic circuit. We do not know the extent of the volume changes in our cases, but we have tried to minimize them by using a dose known to be effective but too small to cause a fall in systemic pressure with the patient lying down. It must be admitted, however, that volume changes may play a part in altering pressure/ flow relations in the lungs in our cases, and must certainly be a factor when such large doses of hexamethonium are given as by Davies et al. and Scott $e t$ al. Changes in cardiac output and pulse rate may be discounted, for they were minimal and inconsistent. The effect on tonus of the pulmonary veins and left atrium is unknown; clearly, any appreciable decrease in tone would, by redistributing blood within the lungs, profoundly affect pressure/flow relations in the capillary bed. Another possible factor is a change in left ventricular filling pressure. In Cases 3 and 8, there was, initially, a fall in left ventricular work on effort. Although hexamethonium did not affect resting dynamics, 
a corresponding amount of exercise now produced a striking rise in left ventricular work (Fig. 5). A similar change was seen in Case 1 following operation. This may be entirely due to diminished resistance to blood flow through the lungs and, in consequence, improved left ventricular filling, but it is also possible that left ventricular failure, with a rise in left ventricular filling pressure, occurred during the first period of effort. Direct catheterization of the left ventricle through a needle inserted into the left auricle has shown that, in pure mitral stenosis, the filling pressure of the left ventricle at rest may be as high as $11 \mathrm{~mm}$. $\mathrm{Hg}$. (Fox et al., 1956). It is probable that more than one of these factors is concerned but our data do not enable us to distinguish between them.

The mechanism whereby changes in $P C V$ or pulmonary venous pressure-and we are unable to distinguish between them-affects vascular hindrance in some cases but not in others remains obscure. When the resistance rises it must be due, partly or wholly, to active contraction of the muscular pulmonary arteries, but we have brought forward evidence that the sympathetic system is not concerned. There must be, however, in the normal lung, some mechanism for maintaining a higher vascular tone in the dependent parts of the lung, for, in the erect position, there is a $20 \mathrm{~mm}$. $\mathrm{Hg}$. pressure-gradient between apex and base. It is also a not uncommon post-mortem observation that in cases of mitral stenosis with high resistance, there are scattered areas of pallor usually confined to the lower lobes (Campbell, 1956). An attractive and reasonably satisfying hypothesis would be a local veno-arterial or capillary-arterial reflex, similar to that reported by Haddy and Gilbert (1956) to occur in the limb vessels of the dog. These workers found that raising the pressure in a particular vein caused a variable, and often disproportionate, rise in pressure in the corresponding arteriole; the reflex persisted after nerve block and did not necessitate an intact sympathetic supply. A somewhat similar mechanism had been noted in the limbs of rabbits by Girling (1952). Such a hypothesis would harmonize with the belief that anoxia, one of the few stimuli that will cause vasoconstriction in the normal lung, also acts through a local reflex, for the effect is known to be independent of autonomic innervation (Liljestrand, 1948; Nisell, 1951a and $b$ ).

The slight increase in total resistance noted in four of eight cases following atropine may be ascribed to the induced tachycardia with consequent reduction in diastole. We had hoped that, by selecting cases of auricular fibrillation fully under the influence of digitalis, we would avoid the complication of severe tachycardia, but this was not the case. Kaunitz and Andersen (1954) suggested that, in the dog, vasoconstrictor fibres to the lungs might be carried in the parasympathetic. nerves, but our results yield no confirmation that this is so in man.

\section{Summary AND CONCLUSIONS}

Hexamethonium bromide was injected into the pulmonary artery in ten cases of mitral stenosis with clinical evidence of pulmonary hypertension. The effects produced on circulatory dynamics both at rest and on effort are reported.

Hexamethonium often lowered the pulmonary vascular resistance and this occurred in association with a reduction in pulmonary capillary venous pressure.

It is suggested that hexamethonium acts by lowering the pulmonary capillary venous or pulmonary venous pressure and that this causes a fall in pulmonary vascular resistance by means of a local reflex which is not under autonomic control.

Atropine was administered intravenously to eight subjects with severe mitral stenosis and auricular fibrillation fully under the influence of digitalis. It was not found to have any consistent effect.

We thank Professor Colin Campbell for his help regarding certain pathological features of the lungs in mitral stenosis, Dr. A. Morgan Jones for his encouragement and for permission to examine patients under his care, and Mr. R. C. de Meneaud for technical assistance. Finally, we thank our patients for their willingness to co-operate in long and arduous observations. 


\section{REFERENCES}

Annotation in the Lancet, 1, 372, 1956.

Bayliss, R. I. S., Etheridge, M. J., and Hyman, A. L. (1950). Lancet, 2, 889.

Campbell, C. (1956). Personal Communication.

Davies, L. G., Goodwin, J. F., and Van Leuven, B. D. (1954). Brit. Heart J., 16, 440.

Donald, K., Bishop, J. M., and Wade, O. L. (1954). J. Clin. Invest., 33, 1146.

Eliasch, H., Wade, G., and Werko, L. (1952). Circulation, 5, 271.

Fox, I. J., Wakai, C. S., Connolly, D. C., and Wood, E. H. (1956). Proc. Staff Meet. Mayo Clinic, $31,126$.

Girling, F. (1952), Amer. J. Phys., 171, 204.

Haddy, F. J. and Gilbert, R. P. (1956). Circulation Research, 4, 25.

Halmagyi, D., Felkai, B., Ivanyi, J., Zsoter, T., Tenyi, M., and Szucs, Z. (1953). Brit. Heart J., $15,15$.

Kaunitz, V. H., and Andersen, M. N. (1954). J. Thorac. Surg., 27, 55.

Kopelman, H., and Lee, G. de J. (1951). Clin. Sci., 10, 383.

Liljestrand, G. (1948). Arch. intern. Med., 80, 162.

Mackinnon, J., Vickers, C. F. H., and Wade, G. (1956). Brit. Heart J., 18, 442.

Meriel, P., Botinelli, R. Calazel, P., and Cassagneau, J. (1953). Arch. Mal. Caur., 46, 329.

Nisell, O. (1951a). Acta Physiol. Scand., 23, 85. (1951b), Acta Physiol. Scand., 23, 361.

Scott, R. C., Kaplan, S., and Stiles, W. J. (1955). Amer. Heart J., 50, 720.

Storstein, O., and Tveten, H. (1954). Scand. J. Clin. Lab. Invest., 6, 169.

Wade, G. (1952). M.D. Thesis, University of Manchester.

, and Ball, J. (1956). Quart.J. Med., in the press.

Werko, L., Eliasch, H., Gidlund, A., and Lagerlof, H. (1952). Quart. J. Med., 21, 361.

Werko, L., Eliasch, H., Berglund, F., and Crafoord, C. (1952). Ann. Surgery, 135, 290.

Witham, A. C., and Fleming, J. W. (1951). J. Clin. Invest., 30, 707.

Wood, P. (1954). Brit. med. J., 1, 1051. 